\title{
Towards a Framework for Attention Cueing in Instructional Animations: Guidelines for Research and Design
}

\author{
Björn B. de Koning • Huib K. Tabbers • \\ Remy M. J. P. Rikers • Fred Paas
}

Published online: 8 April 2009

(C) The Author(s) 2009. This article is published with open access at Springerlink.com

\begin{abstract}
This paper examines the transferability of successful cueing approaches from text and static visualization research to animations. Theories of visual attention and learning as well as empirical evidence for the instructional effectiveness of attention cueing are reviewed and, based on Mayer's theory of multimedia learning, a framework was developed for classifying three functions for cueing: (1) selection-cues guide attention to specific locations, (2) organization - cues emphasize structure, and (3) integration - cues explicate relations between and within elements. The framework was used to structure the discussion of studies on cueing in animations. It is concluded that attentional cues may facilitate the selection of information in animations and sometimes improve learning, whereas organizational and relational cueing requires more consideration on how to enhance understanding. Consequently, it is suggested to develop cues that work in animations rather than borrowing effective cues from static representations. Guidelines for future research on attention cueing in animations are presented.
\end{abstract}

Keywords Instructional animations · Cognitive load theory · Instructional design

Recent advances in software and computer technology enable designers of computer-based instruction to use dynamic visualizations, such as animation and video, to help learners remember complex dynamic systems and, ultimately, understand the materials (Lowe 2004). At present, the majority of animations present information in close correspondence with the referential situation, without highlighting the information or providing cues to help learners process the material. However, manipulating the visuospatial characteristics of animations may make them more effective, just as manipulating these aspects in static

B. B. de Koning $(\bowtie) \cdot$ H. K. Tabbers $\cdot$ R. M. J. P. Rikers $\cdot$ F. Paas

Department of Psychology, Erasmus University Rotterdam, P.O. Box 1738, 3000 Rotterdam,

The Netherlands

e-mail: dekoning@fsw.eur.nl

F. Paas

Centre for Learning Sciences and Technologies (CELSTEC), Open University of The Netherlands, Heerlen, The Netherlands 
representations (e.g., enlarging or highlighting information in text and pictures) improves learning (Tversky et al. 2008). We refer to the manipulation of visuospatial characteristics of instructional materials in order to help learners in selecting relevant information, and organizing and integrating the information into a coherent representation as "cueing", which is similar to "signaling" that has its origins in text-processing research and is recently applied to learning from illustrations (Mautone and Mayer 2001; Meyer 1975). Cueing is intended to draw learners' attention to essential elements of the (visual) representation, for instance by increasing the luminance of specific objects in a visual display (e.g., De Koning et al. 2007) or by changing a word's font style to boldface in a text (e.g., Mautone and Mayer 2001). It is important to note that cues do not provide new information or change the content of the instructional materials (Lorch 1989). This paper examines whether cueing approaches that have been successfully used in static representations (i.e., text and visualization) can be effectively transferred to animations in order to improve learning.

\section{Learning from Complex Animations}

In recent years, learning from animations has received a considerable amount of attention from educational researchers (Ploetzner and Lowe 2004). Schnotz and Lowe (2008) define an animation as a dynamic visual representation where the information about temporal change is contained in the difference of object properties between successive frames. Intuitively, animations seem more effective at illustrating the configuration and behavior of complex systems that involve changes of objects and their positions over time than static visualizations. In addition, animations appear to be natural for conveying concepts of change (Tversky et al. 2002), and due to their ability to depict the temporal changes in the operation of complex dynamic systems explicitly, can provide a real-time external representation that can be directly mapped onto the referential situation (Gibson 1979).

Although a review by Tversky et al. (2002) found little evidence that animations were superior to static visualizations (see also Mayer et al. 2005), a meta-analysis by Höffler and Leutner (2007) indicated that under some conditions animations may produce better learning than static visualizations. According to Tversky et al. (2002), failures to find improved learning from animations might result from the fact that animations are often "too complex or too fast to be accurately perceived" (p. 247). Several studies have shown that learning from animations is hindered if presentation speed is too high (e.g., Meyer et al. 2009), or if attention is distracted by irrelevant movements in the animation (e.g., Lowe 1999). Accordingly, several researchers have argued that animations place excessive demands on the learners' cognitive system due to the transitory nature of the presented information and the simultaneous depiction of multiple changes (Ayres and Paas 2007a; Lowe 1999, 2003; Tversky et al. 2002).

First, the transient nature of animations requires learners to process information that is shown very briefly and disappears before it can be selected for further processing, unless they leave some kind of trace in which key information is kept available (Marcus et al. 2006; Paas et al. 2007). When viewing an animation, learners not only need to integrate new information with existing knowledge that is stored in long-term memory (LTM), but also with previously presented information that has to be kept active in working memory (WM). Therefore, the transient nature of animations may cause learners to split their visual attention over different elements that are dispersed over time. This may consequently challenge the resource limitations of the learner's WM (Miller 1956) and hinder learning (Ayres and Paas 2007a; Paas et al. 2003).

Second, trying to understand an animation requires learners to simultaneously attend to many elements that move from one location to the other and might change with respect to 
different perceptual attributes (e.g., color, form, orientation). There is a considerable amount of evidence in the perception literature that such dynamic changes are very effective at capturing attention when searching for specific information, even when they are task-irrelevant (e.g., Franconeri and Simons 2003; Treisman and Gormican 1988). Moreover, Hillstrom and Chai (2006) even suggested that dynamic aspects, such as movements or a sudden appearance of an object, are perhaps the most effective object characteristics for capturing attention in a visual display. Therefore, it is not surprising that learners often have difficulties in focusing their attention on essential information in an animation, as objects that have high perceptual salience due to their movements easily distract them. This might especially hinder learning in situations where the thematically relevant aspects are not the most salient in an animation (Lowe 1999, 2003).

Although the problems resulting from the transient character of animations and the simultaneous presentation of multiple moving elements may occur independently, they will most likely interact. For example, focusing attention seems especially relevant if the information is only briefly available and there is no opportunity to re-inspect it. Therefore, it is crucial that designers of animations have instructional tools at their disposal to guide the learners' attention at the right moment to the right information in the display (Schnotz and Lowe 2008).

It is well established that cueing may help learners extract and process the essential information from static information (Tversky et al. 2008). However, it is possible that cues found to be effective in static instruction are less effective when used with animations. Especially, the transiency in animations provides an extra challenge to the use of cues. Because in animations there is only limited time in which relevant information can receive attention before it disappears and there is a possibility of being distracted by irrelevant movements, guiding attention becomes more difficult because learners should not only be aware of which elements are being cued but also when they are cued. Therefore, cues such as arrows may lack precision required for effective attentional guidance to small and fast changes. Moreover, cueing by changing the properties of a visual representation (e.g., color change) has the advantage of not adding extra elements to the display, but due to the additional demands in animations it may be less clear for learners or they may not have enough time to find out that this manipulation is a cue that is not part of the content of the animation. Consequently, cueing may increase the possibility for causal misinterpretations and increase learning demands to the representation even further by requiring learners not only to identify and process the structure and meaning of the animation but also that of the cues in a limited amount of time.

In the remainder of this article, findings from research on visual attention and attention capturing mechanisms are discussed to specify the perceptual processes involved in cueing. Next, cognitive load theory is introduced as a theoretical basis for the cognitive aspects of cueing. Then, a framework is proposed for distinct functions of cueing based on the cognitive theory of multimedia learning (Mayer 2001) that is supported by research on learning from static representations. Next, existing research on the effectiveness of cueing in animations will be discussed. Then, based on our framework of cueing, we will present recommendations for directing research dealing with cueing in instructional animations and guidelines for instructional design.

\section{Theoretical Accounts of the Effect of Cueing on Perceptual and Cognitive Processing}

Several theoretical models are currently used to describe cognitive processing with regard to learning from animations and multimedia (e.g., Mayer 2001; Sweller 1988). However, 
these models are less explicit about the perceptual processes involved in the initial stages of distinguishing between relevant and irrelevant information. Therefore, to provide a comprehensive account of the effect of cueing in animations, models of visual attention are used to give an account of the perceptual processes involved in cueing in animations and cognitive load theory and Mayer's theory of multimedia learning are used to provide insight into the cognitive processes underlying cueing in animations. Each of the approaches will be discussed in turn.

\section{The effect of cueing on perceptual processes}

Human visual perception is extremely selective. Learners can focus their visual attention only on a small amount of elements of a visual display at once and only a small portion of that information can be subsequently processed in WM (Baddeley 1992). The elements learners will look at are determined by several factors such as the elements' prominence and their level of detail (Winn 1993). Carefully identifying the characteristics that contribute to the perceptibility of information allows the identification of the properties that potentially capture attention in animations and to predict the conditions under which cueing in animations may be effective.

Schnotz and Lowe (2008) have distinguished two features that influence the perceptibility of different elements of animations: visuospatial contrast and dynamic contrast. For visuospatial contrast, an element stands out against surrounding elements because it has other distinctive visual features, such as a different size or unique color. A dynamic contrast occurs if an element's movements and temporal changes establish a figure-ground distinction that in turn captures learners' attention. Numerous studies on visual search and cueing paradigms in visual attention research have offered related suggestions about what object features might capture attention and facilitate the identification of objects or events.

First, there are objects that have distinctive features and therefore differ substantially with respect to the visuospatial distribution of object properties (e.g., color, form). In different visual search paradigms, the unique characteristics of an object that make an object visually more salient by establishing a contrast on one or more perceptual attributes speeds up the identification of target objects irrespective of the number of surrounding objects (Treisman and Gelade 1980; Treisman and Gormican 1988). For example, finding a green digit among red ones reduces the time taken to detect the target because the unique color of the target causes it to be more salient and to pop-out from the background of red distracters. This pattern has been found in particular if the object is relevant for the task (Yantis and Egeth 1999), but even persists if attending to the object that pops-out is known to be irrelevant and disadvantageous to the performance of the task (e.g., Pashler 1988; Theeuwes 1991, 1992). Especially, unique colors (e.g., Nagy and Winterbottom 2000; Turatto and Galfano 2000, 2001; Turatto et al. 2004) and luminance contrasts (Enns et al. 2001) seem very effective at capturing attention.

Second, a number of researchers have emphasized the importance of temporal discontinuities in object properties present in a visual scene, that is, abrupt onsets or changes in objects over time ("transients") to capture visual attention, especially when they occur rapidly. In several studies, Jonides and Yantis (1988; Jonides 1981; Yantis and Jonides 1984) have demonstrated that onset transients effectively capture attention. Furthermore, Miller (1989) showed that attention is not only controlled by sudden onsets, but that attention is attracted by all sudden changes in a visual scene. Indeed, in line with the dynamic default hypothesis (Franconeri and Simons 2003), which states that all 
dynamic events garner attentional priority, different types of motion, such as the start of movement (e.g., Abrams and Christ 2003), moving, looming, and disoccluding objects (Franconeri and Simons 2003) may draw attention and cause people to fixate on the target object (Godijn and Theeuwes 2002). However, it is important to note that motion per se does not attract attention. Attentional capture only occurs when movements segment an object from its background (Hillstrom and Yantis 1994).

The findings suggest that bright colors and coarse movements within animations may have their own intrinsic cueing effects and hence have the potential to capture learners' attention almost automatically (i.e., inherent content cues). However, cues to enhance perceptual and cognitive processing are not conceptualized as part of the content. Rather, they are considered to be artificially added to animations (e.g., arrows) with the intention of (re)directing attention to aspects of the display that deserve the learners' attention (i.e., instructional cues). For this purpose, manipulating attention-gaining features like colors and movements might be effective cues for minimizing the salience of irrelevant elements (e.g., dimming irrelevant bright colors) and focusing on thematically relevant information (e.g., flashing essential parts).

In short, a large amount of evidence from selective visual attention research has shown that an object may automatically capture attention or stand out more easily if (1) the object differs from other objects on at least a single attribute such as color, or if (2) objects move from one location to another, irrespective of whether the movements foster or hinder the learning process. Because both of these aspects are likely to be present in complex animations, the design of cues for animations should be based on these same properties to effectively redirect learners' attention to relevant elements.

The effect of cueing on cognitive processes

Several instructional design theories, such as Mayer's cognitive theory of multimedia learning (Mayer 1997, 2001) and Sweller's cognitive load theory (Sweller 1988, 1999) provide an explanation for the effect of cueing in terms of the limitations of human information processing resources. A central notion in both theories is that the cognitive system consists of a WM that is relatively limited both in capacity and duration and a LTM that is assumed to have an unlimited capacity to store new information (Cowan 2001; Miller 1956). According to these theories, directing learners' available resources to the learning process itself rather than to irrelevant features of instructional materials is therefore central to designing instruction.

According to Mayer (1992), meaningful learning requires the learner to select relevant information, organize that information into a coherent representation, and integrate this representation into existing knowledge. This is only possible if the elements that have to be mentally combined are simultaneously active in WM (Mayer 2001). WM thus plays an essential role because this is considered the structure, where the selection, organization, and integration processes take place. However, sometimes these processes may be cognitively demanding at the expense of mental resources that could otherwise be allocated to understanding the content. According to the cognitive load theory, three types of cognitive load can be identified (Paas et al. 2003): (1) intrinsic cognitive load that is inherent to the task and consists of interacting information elements that must be processed simultaneously in WM to understand the content; (2) extraneous cognitive load, which is imposed by processes that do not contribute to learning (e.g., searching a picture for referents mentioned in a text) and is evoked by the instructional design; and (3) germane cognitive load, which is imposed by processes that are effective for learning (e.g., integrating new information into already existing schemata) and is also evoked by the instructional design. 
The construction of adequate and rich schemata may be especially challenging in learning from dynamic visualizations of specialized subject matter. Because of the amount and complexity of information, learners have to process when studying animations the selection of relevant elements, their organization, and the construction of links between textual and/or pictorial elements are likely to impose a high cognitive load. As cues focus the learners' attention on the most relevant information, visual search is reduced and less visuospatial resources are required to control the execution of eye movements. Thereby, cueing reduces extraneous cognitive load associated with locating relevant information. This frees up mental resources that can be used for cognitive activities that are directly relevant for schema construction (e.g., integration of information).

Evidence that cued instruction requires less cognitive resources comes from a study on text processing by Britton et al. (1982). In their study, students read a cued or an uncued text while at the same time their reaction times to a secondary task were measured as a measure of cognitive load. Results indicated that texts containing cues about relevant concepts and their relations required less cognitive resources to process than texts without such cues. Moreover, in a study comparing groups who studied cued or uncued texts, Loman and Mayer (1983) showed that the reduction in cognitive load in the cued condition allowed learners to construct a deeper representation of the content, as indicated by better retention and transfer performances.

Research on multimedia learning that used a subjective rating scale as an indicator of experienced cognitive load (Paas 1992; Paas and van Merriënboer 1993, 1994; Paas et al. 2003) provides some evidence for the effects of cueing on cognitive load. In a study by Kalyuga et al. (1999), color-coding cues that linked on-screen text with corresponding parts in an illustration reduced cognitive load and improved learning performance (see also Jamet et al. 2008), suggesting that cues can effectively increase WM resources available for learning. In contrast, Keller et al. (2006) and Tabbers et al. (2004) could not find a reduction of cognitive load but did find better learning performance.

In summary, the effects of cueing on cognitive processing are primarily explained by reduced visual search and the unnecessary load associated with locating relevant information, which frees up WM resources for genuine learning activities. In both text and visualization, research evidence has been found to support this explanation with some studies demonstrating a reduction in cognitive load whereas other studies have reported better learning performance without reduced cognitive load.

\section{A Framework for Classifying Different Functions of Cueing}

So far, it was stressed that both perceptual and cognitive factors have to be taken into account when providing a theoretical explanation for cueing. However, the extent to which cues include perceptual and/or cognitive aspects may depend on the function(s) served by cues. Therefore, we propose a framework for different functions of cueing. The framework is grounded in Mayer's cognitive theory of multimedia learning as the theory's distinction between the processes of selection, organization, and integration of new information provides a solid basis for identifying the three main functions of cueing that might be related to distinct perceptual and cognitive effects: (1) guiding learners' attention to facilitate the selection and extraction of essential information, (2) emphasizing the major topics of instruction and their organization, and (3) making the relations between elements more salient to foster their integration. The rich collection of prior research on cueing that has examined the effects cues have on understanding text and/or illustrations is used to 
provide empirical support for the proposed functions (see the first four columns of Table 1). Each of the functions will now be discussed in more detail.

\section{Guiding attention to essential information}

A crucial part of constructing a coherent representation from instructions is the learners' ability to extract main ideas or concepts that subsequently can serve as the basis for further processing. To what extent learners succeed in this task largely depends on the proper allocation of attention (Gaddy et al. 2001). In general, learners frequently do not possess adequate knowledge to discriminate relevant from irrelevant information and, therefore, may be at risk of focusing on non-essential information or draw inaccurate conclusions (Bromage Mayer 1981; Graesser 1981). For example, learners who are unfamiliar with the subject matter may find it difficult to identify the main themes in a text or select the relevant elements in a picture. Instructional designers can guide the process of attention allocation by using cueing to emphasize content that requires intentional processing. The first function of cueing is thus to emphasize particular information intended to indicate the relevance of the cued content. This kind of cueing is highly specific and unambiguous with respect to the information that is cued (Lorch 1989). For example, color variations in illustrations or underlining words in a text are means to stress the importance of cued information.

Numerous studies on text comprehension that have used memory performance (i.e., recall) as an indicator of attentional processing have consistently shown that cues improve the recall of the content they emphasize (Cashen and Leicht 1970; Dee-Lucas and DiVesta 1980; Fowler and Barker 1974; Hartley and Trueman 1985; Lorch and Lorch 1996). Memory for uncued content is unaffected (Foster 1979; Golding and Fowler 1992), inhibited (Glynn and DiVesta 1979), or sometimes even enhanced (Cashen and Leicht 1970). These findings suggest that emphasizing particular content may guide learners' attention to essential information but does not necessarily reduce attention for uncued information. In addition, Lorch et al. (1995) and Lorch and Chen (1986) have demonstrated that cues slow down the reading times for text processing, which provides direct evidence that effects of cueing on memory are mediated by processes of attention.

Furthermore, studies examining the influence of emphasizing specific content in illustration-based problem-solving tasks support the notion that cueing can guide attention and subsequent cognitive processing. Using Duncker's (1945) radiation problem, Thomas and Lleras (2007) and Grant and Spivey (2003) demonstrated that by redirecting the learners' attention to critical elements of the problem using for example color highlights led to more correct problem-solutions than studying the same diagrams without such cues. This is in line with Park and Hopkins' (1993) recommendation to use perceptual features (e.g., color, motion) to guide learners' attention to critical information during (visual) instruction. A similar argument was made by Wetzel et al. (1994) for improving the learning effectiveness of video-based instruction.

In short, the empirical evidence on cueing in text and/or illustrations clearly demonstrates that perceptually emphasizing information facilitates the selection of relevant elements and subsequently improves learners' retention of cued content and improves problem solving.

Emphasizing the organization of instruction

The global organization of instructions is usually made up of individual parts and subparts that together constitute a hierarchical structure (Schnotz and Lowe 2008). Therefore, 


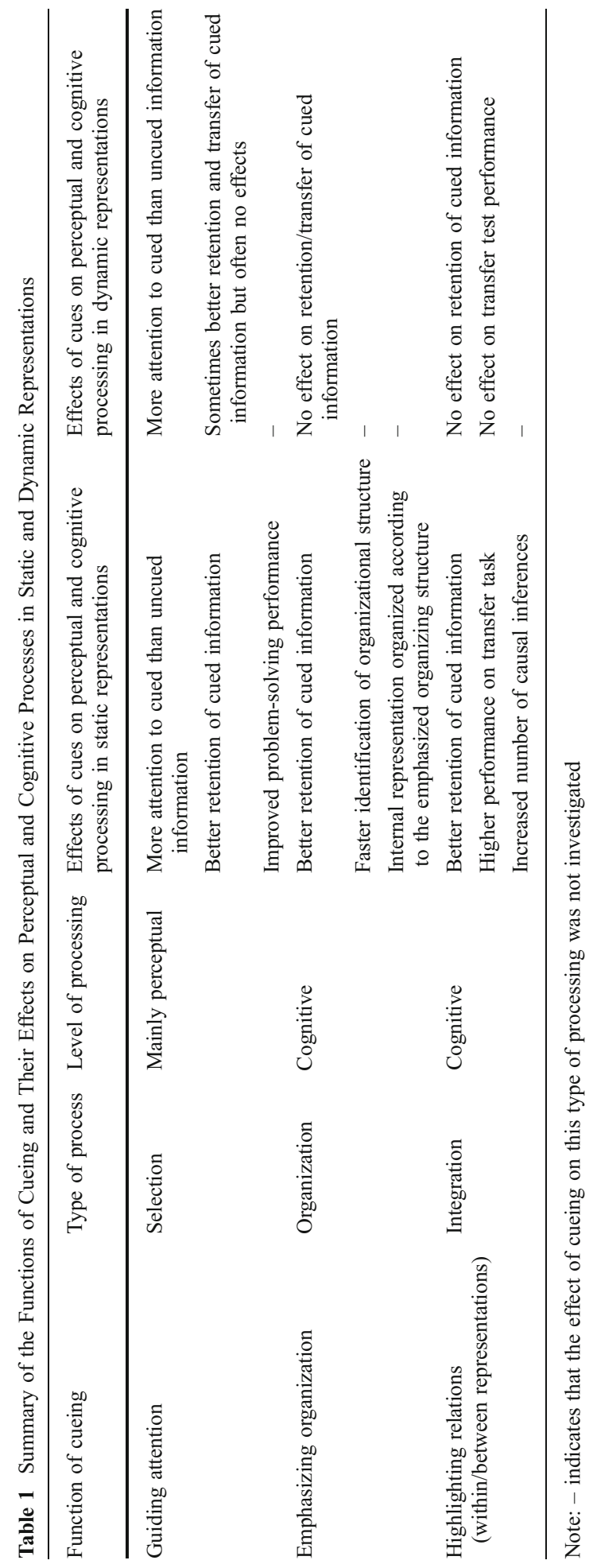


identifying the individual elements and combining them into a coherent structure are essential aspects of the comprehension process. Representing the organizational structure of a text, for example, requires learners to identify individual topics, topic shifts, and determine how topics are related (Lorch et al. 1985). Indeed, according to Gernsbacher's structure-building framework (Gernsbacher et al. 1989, 1990), at the end of a section learners may engage in processing to integrate a new topic with previous related topics in the text, or treat the new topic as independent of previous text content. Consequently, at each transition between topics, the overall organizational structure will be updated (Lorch et al. 1985). However, discerning the topic structure from text passages often fails if learners are not adequately supported with cues that emphasize the text's global topic structure (Loman and Mayer 1983; Lorch and Lorch 1995; Rickards et al. 1997). Therefore, a second function of cueing is to emphasize the organization of instructions to help learners to accurately represent the structure of the presented information.

A variety of cueing techniques, such as outlines and headings, is available to assist learners in identifying the main topics of texts and their organization. There is abundant evidence that organizational cues facilitate text processing, as demonstrated by studies reporting shorter reading times for topic-introducing sentences when an outline of the topical structure of a text is provided or when the topic shifts are cued by the preceding text (Lorch et al. 1985, 1987). In addition, organizational cues improve the retention for text topics and their organization (Loman and Mayer 1983; Lorch and Lorch 1985, 1995, 1996; Lorch et al. 1993; Meyer et al. 1980), although this may occur at the cost of remembering deemphasized content (Mayer et al. 1984). Specifically, cues that emphasize the topic structure alter the organization of text in memory, without necessarily influencing the amount of content recalled. That is, the organization of content in recall closely resembles the structure of the text (Lorch and Lorch 1985, 1995, 1996; Lorch et al. 1993). However, organizational cues are only effective in altering the organization of content in memory if the instructions are complex and do not involve a well-defined structure or contain many topics (Lorch 1989; Lorch and Lorch 1996; Meyer 1975).

Despite a large amount of studies investigating the effects of organizational cues on text processing, very little research has examined the organizational function of cueing in visualizations. Visualizations may effectively represent the structure of non-moving phenomena by showing an object's (sub)parts and their spatial relations (Tversky et al. 2002). Graph comprehension research indicates that, depending on how information is structured and hence what information is emphasized in a graph's perceptual organization, different elements are extracted for constructing a mental representation (Shah et al. 1999). Therefore, Shah et al. (1999) argued that representing graphical information in a way that makes important information (i.e., trends, associations) more salient and requires less mental computations facilitates comprehension in terms of retention and transfer performance. However, the organizational structure may be difficult to depict accurately in a static visualization when temporal dimensions are involved such as when depicting a complex dynamic system (e.g., cardiovascular system). For example, the "exploded diagrams" that show the components of a complex dynamic system slightly separated from their original location, often fail to provide a good overview of the sequence of assembly. Therefore, in their analysis of the characteristics of what constitutes good graphics, Tversky et al. (2008) concluded that to accurately identify the structure of dynamic events in static visualizations cueing devices such as numbers and arrows representing a sequence need to be included. Despite many examples of organizational cueing in static visualizations, the effectiveness of organizational cues on learning from static visualizations involving a temporal dimension has yet to be investigated systematically. 
In short, research on the effects of cueing the organizational aspects of texts or illustrations shows that cues may facilitate the identification and the subsequent representation of the material's structural organization and improve retention performance. It should be noted, however, that most of this evidence is based on text-processing research.

Integrating elements within and between representations into a functional model

For learners to build a coherent and integrated representation of the content of instructions, it is insufficient to merely attend to key elements and the structural features of the instruction (with or without the help of cues). Rather, several important processes such as making causal inferences and being aware of temporal dimensions of information are central to building a coherent and integrated functional representation (e.g., Kieras and Bovair 1984). Because these cognitive processes are deeply constructive activities, they require considerable cognitive capacity and will only contribute to learning if the total cognitive resources are not exceeded.

It is important to make a distinction between cueing relevant concepts and the content's structural organization (Meyer 1975), and cueing the (causal) relations between concepts (Mayer et al. 1984). Whereas organizational cues operate at a global level to point out the main topics of instruction, relational cues that indicate connections between related elements and are intended to foster the integration of these elements operate at a more local level. Thus, the third function of cueing is to construct an integrated mental representation by guiding the process of attending to complex relations between elements. This function can be divided into two categories: (1) cueing to emphasize the relation between two elements within a single representation (e.g., text or picture) and (2) cueing to draw attention to connected elements in different representations (e.g., text and picture).

\section{Relating elements in a single representation}

It is common in expository texts or complex illustrations that elements having a relation with respect to content or function may be difficult to find and link because they are widely separated across the content (Lowe 1989). Without any guidance emphasizing the important relations, learners may fail to integrate all information into a coherent representation because searching for related elements and trying to relate them may impose a high cognitive load. In fact, there is substantial evidence that using cues explicating the relations between elements in an expository text, such as cross-referencing words or phrases (e.g., "Recall our earlier discussion of..."), helps to process the content more slowly and improves memory for cued content (Glover et al. 1988). In addition, emphasizing the causal links in a description of a causal system with relational cues (e.g., "because of this...") fosters the integration of information as indexed by improvements on transfer tasks (Loman and Mayer 1983; Mayer et al. 1984; Mautone and Mayer 2001). However, cueing does not always result in an integrated representation. For example, Harp and Mayer (1998) did not find beneficial effects of relational cueing sentences (e.g., "Each of the steps are related, in that one step causes the next to occur") on transfer using a well-structured text with simple relations. This suggests that cueing improves the integration process only if the content is ill-defined and relatively complex. In short, cueing the relations between concepts in a single representation when they are - perceptually - less clear or not easily found may facilitate schema construction processes.

Furthermore, sometimes, particularly in visualizations, information can only be depicted indirectly and therefore has to be inferred like information about function, the sequence of operations and their causal outcomes in visualizations (Tversky 2001). 
Previous research has shown that the process of inferring dynamic information from static pictures imposes a high extraneous load on the learner and causes errors (Hegarty 1992). Therefore, graphical cues such as arrows and lines are often suggested to explicate causal relations that are unclear or too implicit in the presentation (Tversky et al. 2000, 2008). It is important to note that while similar graphical cues may be used for guiding attention to specific information, their purpose as a relational cue is to make a sequential or temporal relation more explicit instead of merely emphasizing a single location.

The few studies that have empirically investigated cues to explicate relations provide evidence that enriching a static illustration with graphical cues (i.e., arrows) cause learners to interpret the illustration functionally, as reflected by increased reports of functional inferences and use of verbs of motion and cause in their descriptions of the depicted content and improved understanding of the content (Heiser and Tversky 2002, 2006; Schneider and Boucheix, submitted for publication). Similarly, verbal cueing (e.g., "With the help of the green dot imagine the direction in which gear A turns", see Boucheix and Guignard 2005) focuses attention and encourages learners to infer information and improves the retention and comprehension of a system's operation (Boucheix 2008; Boucheix and Guignard 2005). This is especially true for learners with low spatial abilities (Schneider and Boucheix, submitted for publication). Nevertheless, such cues do not necessarily result in extracting the causal inferences that underlie functional relations (Mautone and Mayer 2007). In short, the majority of empirical evidence shows that functional relation cues that make implicit information (i.e., causal relations) within representations more explicit may improve learning.

\section{Relating elements between representations}

Another way of emphasizing relations concerns making learners aware of the relations between elements that are spatially distributed over different representations, such as in an illustrated text. When graphical information is accompanied by verbal explanations (written or spoken), learners must search through the graphical representation to establish links between elements in the verbal and graphical representations and mentally integrate the two representations to form an accurate mental model (Johnson-Laird 1983). Many interacting elements of information are involved in such search and tracing tasks, which may interfere with learning-related activities. Cognitive load theory suggests that learning may be facilitated by physically integrating the two sources of information to reduce the need for mental integration (Chandler and Sweller 1991) or by presenting information in different modalities, that is, the combined use of visual and auditory channels (see Ginns 2005 for a review on the modality effect). Nevertheless, in complex tasks involving many information elements, learners still may be unable to find the visual referents and establish a link between corresponding elements in the verbal and nonverbal representations. Here, the function of cueing is to explicate such links in order to help learners in building an integrated mental representation.

Several different cueing techniques for pointing out crucial connections between representations in various studies, like flashing to connect related elements (Craig et al. 2002; Jeung et al. 1997), giving related elements the same color (Kalyuga et al. 1999), and orienting cues (i.e., gestures, gaze) as guides to related elements (Lusk and Atkinson 2007), showed that cueing improves the retention for cued content and facilitates the application of learned information as reflected in better performances on problem-solving transfer tasks or reduced problem-solving time. However, the positive effects of relational cues on transfer performance are not always found (Jamet et al. 2008; Tabbers et al. 2004), suggesting that 
the effects of cueing on deep comprehension (i.e., transfer) are less consistent. This is consistent with the findings of Mautone and Mayer (2007) who demonstrated that using color coding and arrows to relate text and illustrations in order to improve graph comprehension only enhanced the number of relational statements but not of causal relations. In addition, cueing only improves retention and transfer performance if the visualization is very complex and cannot be understood without cues that guide learners' processing (Jeung et al. 1997).

Furthermore, research on cueing in hypermedia also demonstrates that relational cues, such as connecting lines and textual hyperlinks, are effective strategies for drawing the learners' attention to specific parts of a visual representation and to relate them to the corresponding textual information (Huk and Steinke 2007; Seufert and Brünken 2006). This indicates that the effects of relational cues on learning are not restricted to instructions that are presented in an easy to follow step-by-step fashion.

In short, the empirical findings provide support that several types of cueing that establish a relation between corresponding elements in different representations improve retention performance. However, the inconsistent results concerning transfer of learning suggest that emphasizing the relation between elements may not necessarily result in a more coherent and integrated representation. In addition, instructional materials seem to require a considerable level of complexity for cueing to be effective.

In conclusion, at least three distinct functions of cueing have been identified, which are supported by prior research on the effects of cues on learning from static instruction. Cues can be effective means for (1) guiding attention to specific locations, (2) organizing information, and (3) integrating individual elements into a coherent representation. Importantly, different types of cues may serve multiple or related functions. Specifically, organizational cues may emphasize several aspects of structure. Moreover, cues may have different functions depending on the medium in which they are used. For example, emphasizing information with color variations may be done in text to stress the importance of that part of the content, whereas in multimedia learning it may be used for making learners aware of connected concepts. Nevertheless, other classifications might be possible, for example, by categorizing cueing based on cognitive outcomes rather than on function. In the next section, the functional framework of cueing will be used as a frame of reference in our discussion of the studies that have applied cueing to learning from animations.

\section{Cueing in Animations}

Several researchers have argued that learning from animations may be enhanced if learners' attention is guided to essential information in an animation (Bétrancourt 2005; Mayer and Moreno 2003; Lowe 1999). For example, Bétrancourt (2005) proposes the "attention guidance principle", stating that for information extraction to be effective, cueing should be used to guide the learners' attention to important components of an animation. However, the use of cueing in animations has for the most part been based on intuitive recommendations that cues will facilitate the learning process and are often not considered as the main variable in the analyses. Nevertheless, very recently, several studies have systematically examined the instructional value of adding one or several cues to an animation. Table 2 provides an overview of the studies on cueing in animations and summarizes their characteristics and main findings.

The studies presented here used cueing to serve at least one of the functions that we described earlier in our framework of cueing. To avoid a redundant presentation of the 
studies that have investigated multiple types of cues in a single study or have studied one type of cue to achieve multiple functions simultaneously, our discussion of the effects of cueing in animations is not structured according to the three functions of cueing specified in our functional framework. Instead, we first describe the studies in which cueing facilitated learning followed by the studies in which cues were not beneficial for learning. The framework is used to identify the type(s) of cueing and the function(s) that cueing was intended to fulfill in each study.

\section{Instructional cues that improve learners' understanding}

Some studies reported a positive influence of cues on learning and memory performance. In an influential study, Mautone and Mayer (2001) investigated whether cueing a systempaced multimedia lesson of the principles of how airplanes achieve lift fosters the construction of a coherent and integrated schema. Cueing was done by varying the tone and pitch of key words or phrases in the narration and/or different types of visual graphical cues, including colored arrows, icons, color coding, and color contrast. Verbal cueing and the colored arrows had the function of guiding learners' attention to essential information, whereas icons were used to emphasize the organization of the instruction. To support the integration process such as inferring causal mechanisms, color coding was used to relate elements between representations and color contrasts were used to relate elements within representations. Results revealed that verbal cueing had a strong beneficial effect on problem-solving transfer, whereas highlighting the components and their relations with visual cues in the animation proved to be ineffective. A plausible explanation for the latter finding that is in line with our framework of cueing might be that the animation itself contained simple elements and relations and had a well-defined structure. That is, the animation was not complex enough to require the extra guidance of the visual cues.

Further, Boucheix and Guignard (2005) studied different types of cueing simultaneously in learning the operation of gears in younger adults. Both visual (i.e., color) and verbal (i.e., text sentence) cues were used to facilitate learners' processing of the animation. Whereas the use of color had the function of guiding attention to essential information, the verbal cues served the function of making (temporal) relations within a representation more explicit. Positive effects of cueing were found on immediate comprehension and delayed retention, especially if learners themselves could control the presentation (see also Boucheix 2008). However, it is not clear from this study which type of cueing or what function of cueing has led to these results as no attempt was made to analyze their effects separately. For example, it seems that the verbal cues not only directed attention but also increased learners' engagement in cognitively processing the animation.

In addition to studies that have found the beneficial effects of verbal cues or verbal and visual cues together, there is evidence that visual cueing alone can also improve the understanding of animations. In a study evaluating students' ability to learn the functioning of enzyme synthesis from a narrated animation, Huk et al. (2003) examined the added value of non-verbal cues. They used color, arrows, and visualized technical terms to serve two functions of cueing. The function of the arrows and the coloring of relevant objects was guiding attention to essential information in the animation. The function of visualizing technical terms was relating elements between representations (i.e., animation and accompanying narration). The results showed that cueing resulted in a better learning performance. Nevertheless, it may be argued that cueing not only related elements from the narration to the corresponding elements in the animation, but also added additional information by displaying multiple technical terms visually that could have served as labels 


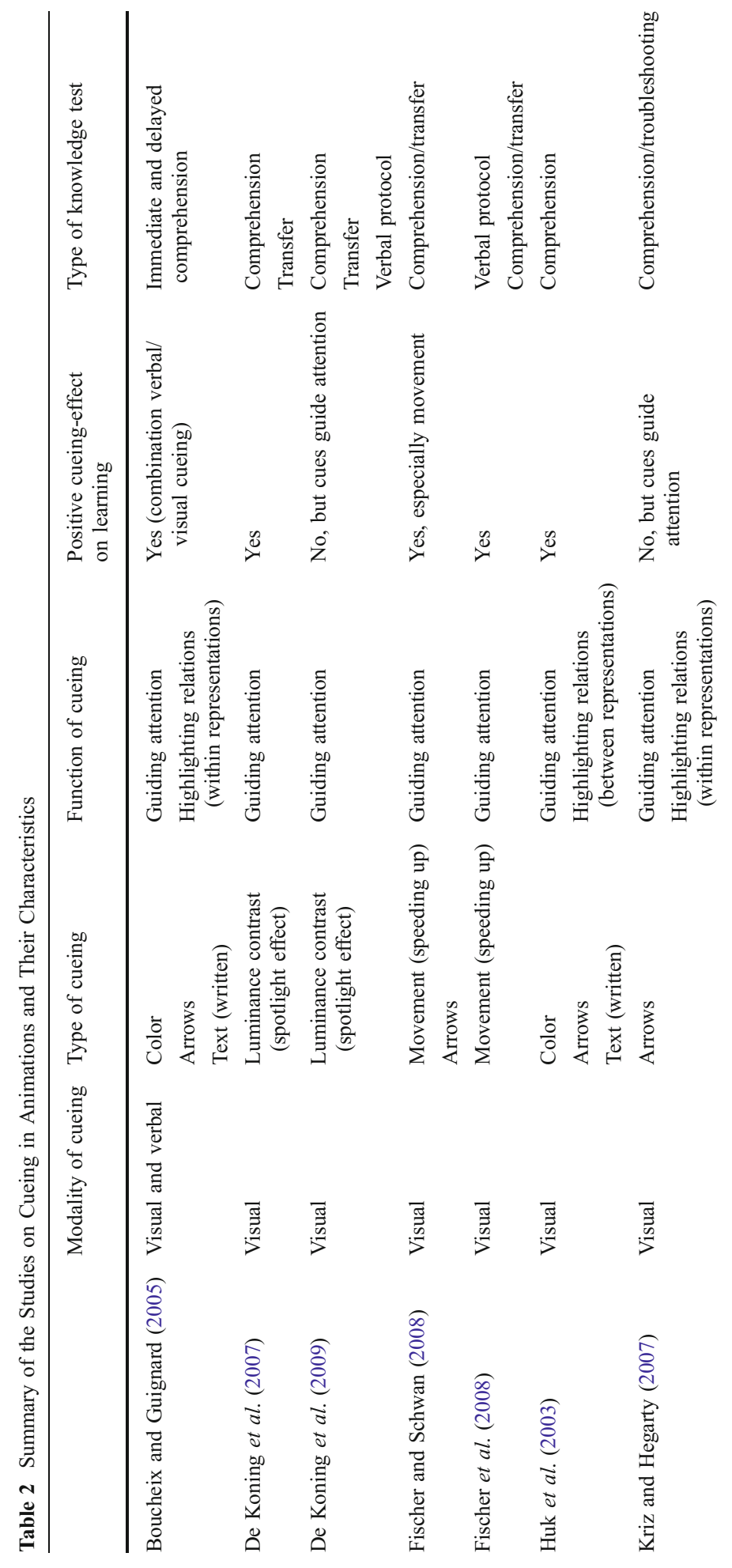




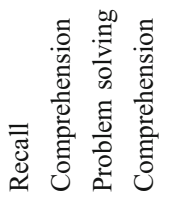

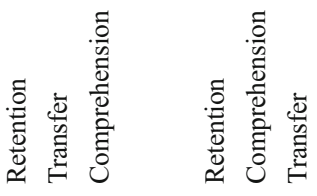

表

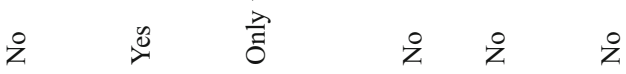

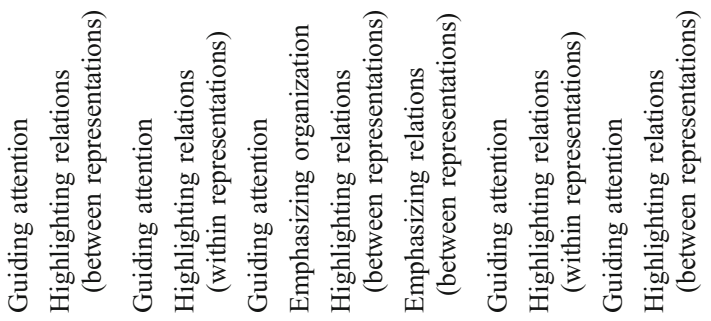

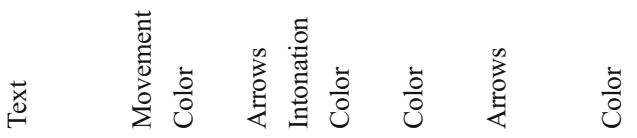

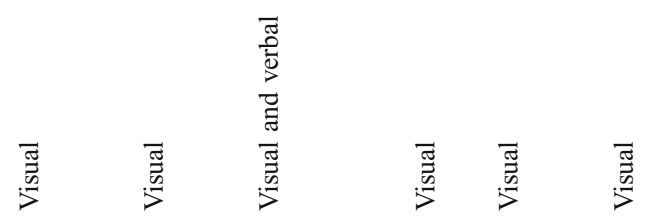

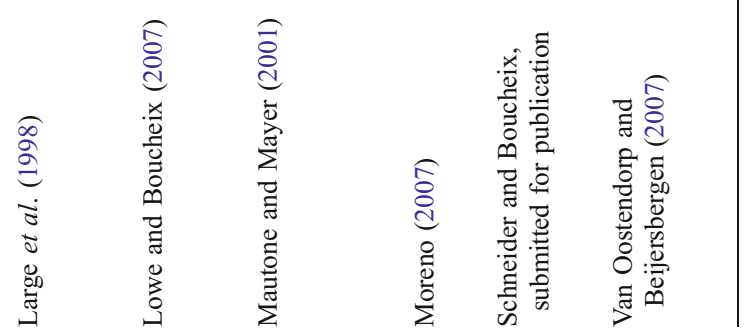


that facilitated cognitive processing over and above emphasizing key information (cf. Mayer 1989). Moreover, the extra information provides information on a deep semantic level and thus cannot be considered a simple visual cue to guide attention.

More convincing evidence for the hypothesis that learning from complex animations can be enhanced by a simple visual cue comes from a study by De Koning et al. (2007). In their study, learners were required to study a non-narrated complex animation illustrating the dynamics of the main processes of the cardiovascular system. One group studied the animation with a visual color contrast cue highlighting one specific process (i.e., the valves system), whereas another group studied the animation without visual cues. The function of the visual color contrast was guiding attention to essential information in the animation. It was found that emphasizing particular content significantly improved comprehension and transfer performance on both the content that was cued as well as on the content that was uncued. No differences were found in the amount of cognitive load, but given the higher learning performances in the cued condition, it was argued that visual cueing leads to a more effective use of WM resources. Together with the study of Mautone and Mayer (2001), this study seems to suggest that the effectiveness of visual cues is dependent on the complexity of the instructional animation and only improves learning if learners need cues to assist them in constructing a coherent representation. This would be in line with the study of Jeung et al. (1997) that has demonstrated that the degree of visual complexity of instruction seems to be a crucial factor for the effectiveness of cueing.

The empirical findings discussed above suggest that deviating from the realistic depiction by manipulating the visuospatial characteristics (e.g., color, luminance) of a complex animation may foster processing and understanding (cf. Dwyer 1978). In addition, Fischer et al. (2008) have argued that also temporal properties (e.g., velocity) of an animation may have visuospatial effects and therefore may be used as cues to (re)direct learners' attention to relevant parts. Changing an animation's speed may influence the relative perceptual salience of the elements in a dynamic display (i.e., dynamic contrast, Schnotz and Lowe 2008), which may effectively influence what information is extracted from the animation for further processing. To investigate whether various presentation speeds emphasize different elements, they set up a study in which learners studied an animation that showed the workings of a pendulum clock at normal presentation speed or at a highly increased presentation speed. The cue (i.e., playing speed) thus had the function of guiding attention to essential information. Results revealed that parts of the clock that are functionally relevant but perceptually less conspicuous in the normal speed version were mentioned significantly more often in the fast version. Moreover, participants in the fast version also included more correct concepts about these parts in their written descriptions. These results provide evidence that temporal manipulation of an animation's presentation speed may increase attention to specific elements and thereby facilitate understanding.

In a related study, Fischer and Schwan (2008; also see Fischer 2008) investigated whether manipulating the speed of the animation (i.e., dynamic cueing) and arrow cues were equally effective at directing attention in an animation. Although the function of both types of cueing was guiding attention to essential information, they differed in how attention was directed (dynamic contrast vs. visuospatial contrast, Lowe and Boucheix 2007). Results demonstrated that altering the playing rate of the animation was a significantly more effective cue for making certain aspects of the animation more salient and directing attention towards those elements than having learners study the animation with locally focused arrow cues. It thus seems that varying temporal properties of animations to serve as cues is more effective for directing attention and improving learning than adding visual cues such as arrows to the display. 
A study by Lowe and Boucheix (2007) provides further support for the notion that dynamic cueing may improve learning. In their study, they examined a form of "continuous cueing" by presenting learners an animation of a piano mechanism with a dynamic spreading color cue. The visual colored path continuously provided a close temporal and visuospatial resemblance to relevant information and occurred synchronous with the visualization of the main causal chains. Cueing improved understanding of the kinematics and functional model of the piano mechanism, suggesting that the spreading color cue effectively enhanced cognitive processing. Lowe and Boucheix (2007) argued that the continuous cue produced an altered viewing pattern, that is, it introduced a new way of looking, which may have stimulated learners to cognitively process the content more deeply. Eye movement data, collected in the study phase, support this conclusion. The success of this type of cueing may lie in the fact that it served not only the function of guiding attention to essential information but also functioned to relate elements within a representation (i.e., it made temporal relations more explicit), which may have increased cognitive engagement and subsequent understanding of the animation.

In short, several studies have demonstrated that verbal and/or visual cues as well as cues that manipulate an animation's temporal properties may improve comprehension and transfer performance, indicating that cueing may be effectively used to improve learning from animations.

Instructional cues that fail to facilitate learning

Despite the generally positive findings of the cueing studies in animations we have discussed so far, an increasing amount of evidence demonstrates that visual cueing does not necessarily improve learning. Within this work, research has explicitly, but not exclusively, focused on the effects graphical cues have on the comprehension of a visual-only animation without text.

In a study comparing two groups of students that studied a user-controllable animation showing the steps in a flushing cistern mechanism with or without arrows to guide attention to essential information and arrows to emphasize causal relations between components or inferences, Kriz and Hegarty (2007) found no evidence of the benefit of cueing on comprehension. To investigate why visual cueing did not produce the expected learning benefits, Kriz and Hegarty (2007) set up an eye-tracking experiment to test whether the arrow cues captured attention and caused learners to look at the cued information. Interestingly, results revealed that the arrow cues directed more attention to relevant information, but this did again not result in a better understanding of the information presented in the animation than studying an animation without visual cues (see also Schneider and Boucheix, submitted for publication).

In a related study, De Koning et al. (2009) also tried to identify the underlying mechanism of attention cueing. In their study, eye tracking and verbal reporting techniques were used to unravel the perceptual and cognitive processes involved in learning from an animation of the cardiovascular system in which none, one, or all of its subsystems were successively cued using a spotlight cue (i.e., luminance contrast). The function of the spotlight cues was guiding attention to essential information. Results paralleled those of Kriz and Hegarty (2007). Thus, both studies suggest that visual cues effectively capture attention, but do not necessarily improve understanding of the content. This pattern of findings may be particularly true for learners with low spatial abilities (Schneider and Boucheix, submitted for publication). A critical requirement for cueing to be effective is that the cues are designed to facilitate rather than to interfere with the processing of an animation. In fact, an improper use of cueing might be ineffective and even increase cognitive load on the learner. This was demonstrated in a study by Moreno (2007), in which prospective 
teachers studied effective teaching skills with or without visual cues. In the cueing condition, the critical teaching skills that were visualized in the animation were highlighted in a bright red color on a step laddered list containing the labels for each skill. Cueing the labels accompanying the skills when they were illustrated in the animation had the function of guiding attention to essential information and relating connected elements between representations. Results showed that the cues did not improve learning performance. Moreno (2007) argued that cueing may have forced learners to spatially split their visual attention between the animation and the highlighted labels that were presented side-by-side, and therefore may have interfered with the learning process. Moreover, this study indicates that the effects of highlighting multiple elements simultaneously without a specific order may hinder learning. Visually highlighting to relate skills and labels to try to control cognitive load may have activated another cause of extraneous load (i.e., splitting one's attention between different representations), which is indicative of the magnitude of the cueing effect and the sensitivity of cueing to individual design features (Ayres and Paas 2007b).

Similarly, Large et al. (1998) studied the effects of cueing in an animation of the cardiovascular system by using text captions (e.g., "This animation shows the flow of blood through the RIGHT side of the heart"). The captions were fragments of the textual description that were added to the animation and thus did not provide new information. Specifically, the functions of the captions were directing attention to essential information in the animation and relating elements between representations by placing captions in the animation to establish a link between specific parts of the animation and the accompanying textual description. Adding captions to the animation did not improve learners' understanding of the system, especially for complex content. The authors believed that this lack of effect may be due to the labels that were included in the animation. As labels are known to improve memory performance themselves (Mayer 1989), they may have made the captions redundant, which consequently added little to understanding the content. Hence, the characteristics of an animation and cueing influence each other and should be properly aligned to optimize the effectiveness of cueing in animations.

Furthermore, Van Oostendorp and Beijersbergen (2007) studied the effects of cueing by highlighting a part of the animation and simultaneously placing a dot before the sentence referring to that part of the animation. The functions of the cues were guiding attention to essential information in the animation and relating elements between representations. Results revealed that the cueing condition did not perform better than the no-cueing condition. A reason for this might be that in contrast to the color coding relating specific words and small pictorial elements used by Kalyuga et al. (1999), cueing in the Van Oostendorp and Beijersbergen study did not relate specific concepts in the text with the corresponding elements in the visualization. This suggests that cueing might not have been specific enough to facilitate processing in this study.

In summary, an increasing number of studies demonstrate that cueing in animations does not facilitate cognitive processes that foster deep understanding such as making causal inferences and forming an integrated representation. If any cueing effects are observed, they tend to be restricted to enhancing lower-level processes, such as identifying, selecting, and extracting information.

\section{Discussion}

This article examined the transferability of cueing methods that have proven to be successful for facilitating the processing of text and/or static visualizations to processing 
instructional animations. The main finding of our analysis of the effectiveness of cueing in animations is that the evidence is mixed. Table 1 summarizes the main perceptual and cognitive effects of cueing on learning from dynamic and static representations. It is important to note that studies on cueing in animations have investigated some functions of cueing more extensively (e.g., attention-directing function) than others (e.g., organizing function) and did not always provide straightforward interpretations of the effects of the functions of cueing. Regarding the function of focusing attention, the findings indicate that cues that highlight specific locations can be effectively used to guide the process of selecting relevant information in animations, but do not necessarily help learners to infer crucial causal relations. Furthermore, cues that emphasize the relations between elements within and/or between representations to enhance their integration have mainly shown no benefits for learning from animations. However, some studies did show better learning with relational cues, but were unable to solely ascribe the improved learning to the relational cues. Moreover, organizational cues that highlight an animation's structure have also not yet proven to be successful. Overall, the conclusions regarding the effectiveness of the different functions of cueing in animations are disappointing and less clear than in learning from text and static graphics.

There are several arguments as to why cueing approaches that have proven to be successful in learning from static representations do not seem to improve learning in animations: (1) cues as they have been used until now, do not have their potential fully exploited yet, (2) cues guiding learners' attention to specific screen locations are overridden by attention-catching elements in an animation, and (3) learners do not perceive cues as relevant for learning.

\section{Cues do not have their potential fully exploited}

An interesting observation is that many studies examining cueing in animations did not identify the unique function of each cue and showed a large diversity in design considerations (e.g., narration or not, pacing or not). Specifically, using cues with multiple functions such as in the Kriz and Hegarty (2007) study might confuse learners and hinder learning. Moreover, not every cue engaged learners in meaningful learning activities like in the Moreno (2007) study, in which the effectiveness of relational cueing may have been reduced because cues required processing that did not seem to be relevant. Also, several studies have used cues that lack specificity (e.g., Van Oostendorp and Beijersbergen 2007). However, even effectively designed cues that guide learners' attention to specific parts do not guarantee enhanced understanding. Rather, the studies of Kriz and Hegarty (2007) and De Koning et al. (2009) suggest that not only the time spent on task-relevant information but also what constructive activities (e.g., generating inferences) are employed within that period of time determine whether learners will reach a thorough understanding. Thus, cueing seems very helpful for guiding attention to specific parts of an animation but it is not sufficient for building a good conceptual understanding from an animation.

In sum, at this point in time, the majority of studies did not use cues in a very well thought-out way, which does not allow us to draw any generalizable conclusions yet. Future studies that use the functional framework will have to reflect the full potential of cueing to improve learning from animations.

The dynamics of an animation override attention cueing to specific screen locations

An alternative explanation for the ineffectiveness of cueing in building an integrated mental model concerns the powerful effect that dynamic characteristics of animations may have on 
the distribution of attention. Elements of an animation that stand out against the rest of the display due to their movements (i.e., dynamic contrast) are likely to attract attention (cf. Hillstrom and Yantis 1994). Consequently, the dynamic capture of attention may outcompete visual cues that direct attention to discrete parts of information and individual locations. In fact, Fischer and Schwan (2008) have provided preliminary support for the assumption that in animations a dynamic contrast due to movements is more effective for capturing attention than a visuospatial contrast. However, the overriding effect of dynamic contrast of animated elements may be overcome by using dynamic cues that make an animation's temporal information such as sequential relations more explicit, but this was only explored in one study (Lowe and Boucheix 2007).

In short, the dynamic contrast created by moving elements of an animation may be more apt at capturing attention than the non-dynamic cueing methods that have been applied to animations and thus may reduce the effectiveness of cueing. Therefore, exploring more dynamic attention guiding mechanisms may be more fruitful (Fischer 2008).

\section{Learners do not perceive cues as relevant for learning}

In animations, learners can directly perceive temporal changes, whereas understanding the same content from static representations requires a process of internal animation (Hegarty et al. 2003). Therefore, learners may be much more cognitively engaged in learning from static representations of dynamic systems than from animations. Asking learners to study and to try to comprehend an animation may be a task that lacks specificity. Therefore, learners often do not know what is expected from them in terms of how thorough they have to study the animation in order to be able to answer the test items and may reduce their efforts to actively process the presented information thereby reducing the possibility of benefiting from cues. Moreover, the fact that cues indicating relevant information and relations are not used as hints to engage in deep learning activities suggests that it may be needed to clarify what cues are presented in animations, how they are intended to facilitate learning, and to instruct learners how to use cues effectively.

In short, although cues may have the purpose of facilitating the organization or integration of information in animations, learners may not use the cues as such due to the learning task being ill-defined.

In conclusion, several factors such as the uncritical application of cueing methods from static instruction to animations, the dynamic character of animations, and the lack of learners' engagement with cues have been discussed as possible reasons for failures to find enhanced learning from cued animations compared with uncued animations. Therefore, it might be suggested that so far the effects of cueing in animations are not studied adequately and might only provide an underestimation of the instructional potential of cues to improve learning from animations.

\section{Implications and Future Research}

At present, it is yet rather unclear under which circumstances cueing in animations will be effective. Therefore, systematically studying the instructional value of the different functions and types of cueing in animations is essential for a better understanding of cueing. In the following, the framework of cueing is used to set out several possible avenues for future research. In addition, guidelines for the instructional design of cueing in animations are derived from the framework that can be tested in further research. 
Guiding attention to essential information

The majority of studies discussed in our analysis have tried to focus learners' attention on specific parts of animations using specific types of visuospatial contrasts. However, for a principled understanding of the effect of cues on guiding attention to essential information more systematic research is needed. For example, it might be studied whether certain types of cues may be more effective than others like enlarging relevant features (i.e., zooming in) or arrow cues. Moreover, it might also be valuable to investigate and refine forms of cueing using a dynamic contrast such as (dis)continuous temporal manipulation (Fischer et al. 2008). Furthermore, it might be interesting to study the manipulation of both visuospatial and temporal aspects like slowing down an animation when highlighted relevant information is encountered.

Another interesting approach would be to investigate attention cueing and simultaneously try to improve learners' cognitive engagement by encouraging them to actively process the animation using techniques that promote constructive processes such as selfexplaining (Roy and Chi 2005). Related to this, it may be worth examining whether giving learners a clear goal or purpose when studying a cued animation may encourage them to perceive the cue as relevant for accomplishing their task and consequently to process the presented information in a more elaborated way.

Furthermore, the level of expertise may have a strong influence on the effectiveness of cueing. According to the cognitive load theory, directing novices' attention to essential parts of animations compensates for a lack of cognitive schemata and frees up cognitive resources for relevant learning activities. However, once learners are capable of discerning relevant from irrelevant parts of animations, visual cues may provide redundant information that cannot be ignored, and hence may cause unnecessary cognitive load that hinders learning (within cognitive load theory referred to as the expertise reversal effect, Kalyuga et al. 2003).

Emphasizing the organization of instruction

Animations usually contain multiple levels of dynamic information because events at the macro level can be decomposed into smaller events at the micro level (Schnotz and Lowe 2008). However, not all levels of dynamic change are of equal importance for the learning task and/or identifying the elements that constitute a group is difficult. For example, someone who is interested in the precise locomotive pattern of reef fish will concentrate on changes at the micro level whereas someone who is interested in the global changes in the movement pattern of reef fish will focus on changes at the macro level. Organizational cues may then be used to help learners in structuring the elements that belong together or distinguishing those that are of relevance for the learners' purpose. For example, the elements that form a unity can be grouped by giving them the same color as an indication that they belong together. Further, an animation's playing speed may be used as a cue to emphasize the level of change at which the organizational hierarchy is studied (Meyer et al. 2009). That is, at higher playing speeds, the macro information tends to be more salient, whereas at lower playing speeds, the micro events become more noticeable. Therefore, playing an animation multiple times at different playing speeds may reveal different levels of the overall dynamic structure. This way the general structure of an animation is emphasized and can be used for further processing such as building a dynamic mental model at a more fine-grained level, that is, the elements that are part of this structure. However, more research is needed to substantiate this claim. 
Integrating elements within and between representations

Several studies in our analysis suggest that visual cues relating corresponding elements between and/or within representations may be ineffective if relational cues lack the appropriate level of specificity and force learners to split their attention across different elements in space to be able to benefit from the cues. Therefore, we propose to study relational cueing more extensively based on a proper task analysis that takes these aspects into account in order to determine whether cues relating elements within representations, between representations, or the combination of both will result in better learning from animations.

In addition, animations differ substantially from static representations in their depiction of causal relations between elements that are distributed over time and the requirements to extract these relations (i.e., "read off" vs. infer). Despite the many unsuccessful attempts to facilitate the extraction of temporal and causal relations with cues such as arrows described in our analysis, the Lowe and Boucheix (2007) study offers a concrete example of how an animation's implicit temporal relations may be made more explicit and can be readily extracted by using a moving cue. More research is needed, however, to develop and test similar and other (dynamic) cueing approaches that explicate the causal relations to be learned in various content areas and with different types of animations. For example, it could be investigated whether an animation of the cardiovascular system can be made more effective if the blood flow is highlighted with a continuous spotlight cue showing its trajectory. It is important to note that dynamic cues to foster the integration process may or may not overlap with dynamic cueing approaches to redirect attention, depending on whether the dynamic cues do or do not explicate spatiotemporal causal information.

\section{Theoretical implications}

Despite the recent studies that have investigated the utility of cues to improve learning from animation, it is yet unclear which aspects of cueing are responsible for its success or failure. Thus far, various theoretical frameworks have been used to explain the effects cues may have on learning from animation, but cognitive accounts predominate. However, the effects on attention of presenting change-related information in an animation and using visual cueing to facilitate perceptual processing suggests that if we wish to explain how and under what conditions cueing can help learning from animations, we need to broaden our approach and extend current cognitive accounts of cueing to encompass perceptual dimensions. For example, both Mayer's cognitive theory of multimedia learning and cognitive load theory provide insufficient understanding of the attentional and perceptual processes of cueing, as assumptions and explanations of these dimensions are not specified.

The few studies that have tried to gain more insight into the crucial factor(s) or underlying mechanism of attention cueing were unable to satisfactorily explain how cues influence processing of an animation. For example, the findings of Kriz and Hegarty (2007) and De Koning et al. (2009) that cues guide attention to crucial locations in the display, provides no solid basis for explaining the cognitive effects of cueing on learning performance. Further, a cognitive load explanation that assumes that studying an animation with attention-directing cues imposes less visual search and extraneous load has yet to be confirmed directly (De Koning et al. 2009). In short, the lack of a comprehensive theory that encompasses all perceptual and cognitive aspects in learning from cued and uncued animations does not allow researchers to fully explain the effects of visual cueing. Future research should be aimed at integrating the predominantly cognitive accounts with current 
theories of visual cognition as a more appropriate framework for investigating how cueing might work in processing animations.

\section{Practical implications}

The extent to which research on the effects of cueing in animations produces general principles or practical guidelines is limited due to the fact that relatively little studies have examined cueing in animations and the findings have been mixed. However, some preliminary guidelines emerge from our analysis:

1. Guiding learners' attention to specific locations in the display with attention-directing cues does not guarantee that learners infer essential causal relations. Therefore, other methods that induce cognitive activity need to accompany attention-directing cues to improve learning from animations.

2. Although several studies have failed to find support for the use of visual cues such as arrows in animations, the recent findings by Lowe and Boucheix (2007) suggest that colorization of relevant features of an animation that occurs in temporal correspondence to events in the animation might improve learner understanding of the material. Thus, visual cues should guide attention both spatially and temporally.

3. Cues designed to facilitate a specific type of processing (e.g., selection, organization, integration) may lose their potency if they are used in such a way that they impose unnecessary processing activities. For example, adding arrow cues to static visualizations to indicate an element's direction of motion may be beneficial, but in animations, it may interfere with the learning process. Therefore, one should first specify the function(s) of cueing and then design the cue(s) accordingly.

Research based on these guidelines can be expected to significantly improve our understanding of the instructional potential of cueing in animations, and subsequently, to promote the development of more refined theoretical approaches. In addition, the three functions of cueing proposed in our functional framework may provide a useful distinction for studying the individual and combined effects of cues on perceptual and cognitive processing. In conclusion, in trying to make animations more effective with cues, it is insufficient to simply apply successful cueing approaches from static representations, but requires the development of cueing approaches that work in animations.

Open Access This article is distributed under the terms of the Creative Commons Attribution Noncommercial License which permits any noncommercial use, distribution, and reproduction in any medium, provided the original author(s) and source are credited.

\section{References}

Abrams, R. A., \& Christ, S. E. (2003). Motion onset captures attention. Psychological Science, 14, 427-432. doi:10.1111/1467-9280.01458.

Ayres, P., \& Paas, F. (2007a). Making instructional animations more effective: A cognitive load approach. Applied Cognitive Psychology, 21, 695-700. doi:10.1002/acp.1343.

Ayres, P., \& Paas, F. (2007b). Can the cognitive load approach make instructional animations more effective? Applied Cognitive Psychology, 21, 811-820. doi:10.1002/acp.1351.

Baddeley, A. D. (1992). Working memory. Science, 255, 556-559.

Bétrancourt, M. (2005). The animation and interactivity principles in multimedia learning. In R. E. Mayer (Ed.), Cambridge handbook of multimedia learning, (pp. 287-296). New York: Cambridge University Press. 
Boucheix, J.-M. (2008). Contrôle d'animations multimédias par des enfants de dix à 11 ans: Quel effet des dispositifs de contrôle? (Control of multimedia animations by children). Psychologie Française, 53, 239-257. doi:10.1016/j.psfr.2007.10.001.

Boucheix, J.-M., \& Guignard, H. (2005). What animated illustrations can improve technical document comprehension in young students? Format, signaling and control of the presentation. European Journal of Psychology of Education, 4, 369-388.

Britton, B. K., Glynn, S. M., Meyer, B. J. F., \& Penland, M. J. (1982). Effects of text structure on use of cognitive capacity during reading. Journal of Educational Psychology, 74, 51-61. doi:10.1037/00220663.74.1.51.

Bromage, B. K., \& Mayer, R. E. (1981). Relationship between what is remembered and creative problem solving performance in science learning. Journal of Educational Psychology, 73, 451-461. doi:10.1037/ 0022-0663.73.4.451.

Cashen, V. J., \& Leicht, K. L. (1970). Role of the isolation effect in a formal educational setting. Experimental Publications System, 7, 240-244.

Chandler, P., \& Sweller, J. (1991). Cognitive load theory and the format of instruction. Cognition and Instruction, 8, 293-332. doi:10.1207/s1532690xci0804 2.

Cowan, N. (2001). The magical number 4 in short-term memory: A reconsideration of mental storage capacity. The Behavioral and Brain Sciences, 24, 87-185. doi:10.1017/S0140525X01003922.

Craig, S. D., Gholson, B., \& Driscoll, D. M. (2002). Animated pedagogical agents in multimedia educational environments: Effects of agent properties, picture features, and redundancy. Journal of Educational Psychology, 94, 428-434. doi:10.1037/0022-0663.94.2.428.

De Koning, B. B., Tabbers, H. K., Rikers, R. M. J. P., \& Paas, F. (2007). Attention cueing as a means to enhance learning from an animation. Applied Cognitive Psychology, 21, 731-746. doi:10.1002/acp.1346.

De Koning, B. B., Tabbers, H. K., Rikers, R. M. J. P., \& Paas, F. (2009) Attention guidance in learning from a complex animation: Seeing is understanding? Learning and Instruction, in press. doi:10.1016/j. learninstruc.2009.02.010.

Dee-Lucas, D., \& DiVesta, F. (1980). Learner-generated organizational aids: Effects on learning from text. Journal of Educational Psychology, 72, 304-311. doi:10.1037/0022-0663.72.3.304.

Duncker, K. (1945). On problem solving. Psychological Monographs, 58, (Whole No. 270).

Dwyer, F. M. (1978). Strategies for improving visual learning. State College, PA: Learning Services.

Enns, J. T., Austen, E. L., Di Lollo, V., Rauschenberger, R., \& Yantis, S. (2001). New objects dominate luminance transients in setting attentional priority. Journal of Experimental Psychology. Human Perception and Performance, 27, 1287-1302. doi:10.1037/0096-1523.27.6.1287.

Fischer, S. (2008). Temporal manipulations in instructional animation design: Is attention guiding thought? Wissensprozesse und digitale Medien (Bd. 10). Berlin: Logos.

Fischer, S., \& Schwan, S.(2008, July). Temporal manipulations for animation design: Presentation speed outperforms cueing. Paper presented at the XXIX International Congress of Psychology (ICP). Berlin.

Fischer, S., Lowe, R. K., \& Schwan, S. (2008). Effects of presentation speed of a dynamic visualization on the understanding of a mechanical system. Applied Cognitive Psychology, 22, 1126-1141. doi:10.1002/ acp. 1426.

Foster, J.J. (1979). The use of visual cues in text. In P. A. Kolers, M. E. Wrolstad, \& H. Bouma (Eds.), Processing of visible language, (Vol. 1, pp. 189-203). New York: Plenum.

Fowler, R. L., \& Barker, A. S. (1974). Effectiveness of highlighting for retention of text material. The Journal of Applied Psychology, 59, 358-364. doi:10.1037/h0036750.

Franconeri, S. L., \& Simons, D. J. (2003). Moving and looming stimuli capture attention. Perception \& Psychophysics, 65, 1-12.

Gaddy, M. L., Sung, Y.-C., \& Van den Broek, P. (2001). The influence of text cues on the allocation of attention during reading. In T. Sanders, J. Schilperoord \& W. Spooren (Eds.), Cognitive approaches to text coherences, (pp. 89-110). Amsterdam/Philadelphia: Benjamins.

Gernsbacher, M. A., Hargreaves, D., \& Beeman, M. (1989). Building and accessing clausal representations: The advantage of first mention versus the advantage of clause recency. Journal of Memory and Language, 28, 735-765. doi:10.1016/0749-596X(89)90006-5.

Gernsbacher, M. A., Vamer, K. R., \& Faust, M. E. (1990). Investigating differences in general comprehension skill. Experimental Psychology: Learning, Memory \& Cognition, 16, 430-445. doi:10.1037/0278-7393.16.3.430.

Gibson, J. J. (1979). The ecological approach to visual perception. Boston, MA: Houghton Mifflin.

Ginns, P. (2005). Meta-analysis of the modality effect. Learning and Instruction, 15, 313-331. doi:10.1016/j. learninstruc.2005.07.001.

Glover, J. A., Dinnel, D. L., Halpain, D. R., McKee, T. K., Corkill, A. J., \& Wise, S. L. (1988). The effects of acrosschapter signals on recall of text. Journal of Educational Psychology, 80, 3-15. doi:10.1037/0022-0663.80.1.3. 
Glynn, S. M., \& DiVesta, F. J. (1979). Control of prose processing via instructional and typographical cues. Journal of Educational Psychology, 71, 595-603. doi:10.1037/0022-0663.71.5.595.

Godijn, R., \& Theeuwes, J. (2002). Oculomotor capture and inhibition of return: Evidence for an oculomotor suppression account of IOR. Psychological Research, 66, 234-246. doi:10.1007/s00426-002-0098-1.

Golding, J. M., \& Fowler, S. B. (1992). The limited facilitative effect of typographical signals. Contemporary Educational Psychology, 17, 99-113. doi:10.1016/0361-476X(92)90052-Z.

Graesser, A. C. (1981). Prose comprehension beyond the word. New York: Springer.

Grant, E. R., \& Spivey, M. J. (2003). Eye movements and problem solving: Guiding attention guides thought. Psychological Science, 14, 462-466. doi:10.1111/1467-9280.02454.

Harp, S. F., \& Mayer, R. E. (1998). How seductive details do their damage: A theory of cognitive interest in science learning. Journal of Educational Psychology, 90, 414-434. doi:10.1037/0022-0663.90.3.414.

Hartley, J., \& Trueman, M. (1985). A research strategy for text designers: The role of headings. Instructional Science, 14, 99-155. doi:10.1007/BF00052394.

Hegarty, M. (1992). Mental animation: Inferring motion from static displays of mechanical systems. Journal of Experimental Psychology. Learning, Memory, and Cognition, 18, 1084-1102. doi:10.1037/02787393.18.5.1084.

Hegarty, M., Kriz, S., \& Cate, C. (2003). The roles of mental animations and external animations in understanding mechanical systems. Cognition and Instruction, 21, 325-360. doi:10.1207/ s1532690xci2104 1.

Heiser, J., \& Tversky, B. (2002). Descriptions and depictions in acquiring complex systems. Proceedings of the 24th Annual Meeting of the Cognitive Science Society. Mahwah, NJ: Erlbaum.

Heiser, J., \& Tversky, B. (2006). Arrows in comprehending and producing mechanical diagrams. Cognitive Science, 30, 581-592. doi:10.1207/s15516709cog0000_70.

Hillstrom, A. P., \& Chai, Y. C. (2006). Factors that guide or disrupt attentive visual processing. Computers in Human Behavior, 22, 648-656. doi:10.1016/j.chb.2005.12.003.

Hillstrom, A. P., \& Yantis, S. (1994). Visual motion and attentional capture. Perception \& Psychophysics, 55, $399-411$.

Höffler, T., \& Leutner, D. (2007). Instructional animation versus static pictures: A meta-analysis. Learning and Instruction, 17, 722-738.

Huk, T., \& Steinke, M. (2007). Learning cell biology with close-up views or connecting lines: Evidence for the structure mapping effect. Computers in Human Behavior, 23, 1089-1104. doi:10.1016/j.chb.2006.10.004.

Huk, T., Steinke, M., \& Floto, C. (2003). Helping teachers developing computer animations for improving learning in science education. Albuquerque, USA: Proceedings of the Society for Information Technology and Teacher Education.

Jamet, E., Gavota, M., \& Quaireau, C. (2008). Attention guiding in multimedia learning. Learning and Instruction, 18, 135-145. doi:10.1016/j.learninstruc.2007.01.011.

Jeung, H., Chandler, P., \& Sweller, J. (1997). The role of visual indicators in dual sensory mode instruction. Educational Psychology, 17, 329-343. doi:10.1080/0144341970170307.

Johnson-Laird, P. N. (1983). Mental models: Towards a cognitive science of language, inference, and consciousness. Cambridge, MA: Harvard University Press.

Jonides, J. (1981). Voluntary versus automatic control over the mind's eye's movement. In J. B. Long \& A. D. Baddeley (Eds.), Attention and performance IX, (pp. 187-203). Hillsdale, NJ: Erlbaum.

Jonides, J., \& Yantis, S. (1988). Uniqueness of abrupt visual onset in capturing attention. Perception \& Psychophysics, 43, 346-354.

Kalyuga, S., Chandler, P., \& Sweller, J. (1999). Managing split-attention and redundancy in multimedia instruction. Applied Cognitive Psychology, 13, 351-371. doi:10.1002/(SICI)1099-0720(199908) 13:4<351::AID-ACP589>3.0.CO;2-6.

Kalyuga, S., Ayres, P., Chandler, P., \& Sweller, J. (2003). The expertise reversal effect. Educational Psychologist, 38, 23-31. doi:10.1207/S15326985EP3801_4.

Keller, T., Gerjets, P., Scheiter, K., \& Garsoffky, B. (2006). Information visualizations as tools for knowledge acquisition: The impact of dimensionality and color coding. Computers in Human Behavior, 22, 43-65. doi:10.1016/j.chb.2005.01.006.

Kieras, D. E., \& Bovair, S. (1984). The role of a mental model in learning to operate a device. Cognitive Science, 8, 255-273.

Kriz, S., \& Hegarty, M. (2007). Top-down and bottom-up influences on learning from animations. International Journal of Human-Computer Studies, 65, 911-930. doi:10.1016/j.ijhcs.2007.06.005.

Large, J. A., Beheshti, J., Breuleux, A., \& Renaud, A. (1998). The effect of animation in enhancing descriptive and procedural texts in a multimedia learning environment. Journal of the American Society for Information Science American Society for Information Science, 47, 437-448. doi:10.1002/(SICI) 1097-4571(199606)47:6<437::AID-ASI4>3.0.CO;2-W. 
Loman, N. L., \& Mayer, R. E. (1983). Signaling techniques that increase the understandability of expository prose. Journal of Educational Psychology, 75, 402-412. doi:10.1037/0022-0663.75.3.402.

Lorch, R. F. (1989). Text signaling devices and their effects on reading and memory processes. Educational Psychology Review, 1, 209-234. doi:10.1007/BF01320135.

Lorch, R. F., \& Chen, A. H. (1986). Effects of number signals on reading and recall. Journal of Educational Psychology, 78, 263-270. doi:10.1037/0022-0663.78.4.263.

Lorch, R. F., \& Lorch, E. P. (1985). Topic structure representation and text recall. Journal of Educational Psychology, 77, 137-148. doi:10.1037/0022-0663.77.2.137.

Lorch, R. F., \& Lorch, E. P. (1995). Effects of organizational signals on text-processing strategies. Journal of Educational Psychology, 87, 537-544. doi:10.1037/0022-0663.87.4.537.

Lorch, R. F., \& Lorch, E. P. (1996). Effects of organizational signals on free recall of expository text. Journal of Educational Psychology, 88, 38-48. doi:10.1037/0022-0663.88.1.38.

Lorch, R. F., Lorch, E. P., \& Matthews, P. D. (1985). On-line processing of the topic structure of a text. Journal of Memory and Language, 24, 350-362. doi:10.1016/0749-596X(85)90033-6.

Lorch, E. P., Lorch, R. F., Gretter, M. L., \& Horn, D. G. (1987). On-line processing of topic structure by children and adults. Journal of Experimental Child Psychology, 43, 81-95. doi:10.1016/0022-0965(87)90052-X.

Lorch, R. F., Lorch, E. P., \& Inman, W. E. (1993). Effects of signaling topic structure on text recall. Journal of Educational Psychology, 85, 281-290. doi:10.1037/0022-0663.85.2.281.

Lorch, R. F., Lorch, E. P., \& Klusewitz, M. A. (1995). Effects of typographical cues on reading and recall of text. Contemporary Educational Psychology, 20, 51-64. doi:10.1006/ceps.1995.1003.

Lowe, R. K. (1989). Search strategies and inference in the exploration of scientific diagrams. Educational Psychology, 9, 27-44. doi:10.1080/0144341890090104.

Lowe, R. K. (1999). Extracting information from an animation during complex visual learning. European Journal of Psychology of Education, 14, 225-244.

Lowe, R. K. (2003). Animation and learning: Selective processing of information in dynamic graphics. Learning and Instruction, 13, 157-176. doi:10.1016/S0959-4752(02)00018-X.

Lowe, R. K. (2004). Animation and learning: Value for money? In R. Atkinson, C. McBeath, D. JonasDwyer, \& R. Phillips (Eds.), Beyond the comfort zone: Proceedings of the 21st ASCILITE Conference (pp. 558-561), Perth.

Lowe, R. K., \& Boucheix, J.- M. (2007). Eye tracking as a basis for animation design. Paper presented at the Bi-annual meeting of the European Association of Research on Learning and Instruction. Budapest, Hungary.

Lusk, M. M., \& Atkinson, R. K. (2007). Animated pedagogical agents: Does their degree of embodiment impact learning from static or animated worked examples? Applied Cognitive Psychology, 21, 747-764. doi:10.1002/acp.1347.

Marcus, N. KhengJoo, A. L., Beng-Fei, K., \& Ayres, P. (2006). Animations with a trace lead to more effective learning than equivalent static graphics. Paper presented at the meeting of the American Educational Research Association, San Francisco, CA.

Mautone, P. D., \& Mayer, R. E. (2001). Signaling as a cognitive guide in multimedia learning. Journal of Educational Psychology, 93, 377-389. doi:10.1037/0022-0663.93.2.377.

Mautone, P. D., \& Mayer, R. E. (2007). Cognitive aids for guiding graph comprehension. Journal of Educational Psychology, 99, 640-652. doi:10.1037/0022-0663.99.3.640.

Mayer, R. E. (1989). Systematic thinking fostered by illustrations in scientific text. Journal of Educational Psychology, 81, 240-246. doi:10.1037/0022-0663.81.2.240.

Mayer, R. E. (1992). Thinking, problem solving, cognition (Secondth ed.). New York: W. H. Freeman.

Mayer, R. E. (1997). Multimedia learning: Are we asking the right questions. Educational Psychologist, 32 , 1-19. doi:10.1207/s15326985ep3201_1.

Mayer, R. E. (2001). Multimedia learning. New York: Cambridge University Press.

Mayer, R. E., \& Moreno, R. (2003). Nine ways to reduce cognitive load in multimedia learning. Educational Psychologist, 38, 43-53. doi:10.1207/S15326985EP3801_6.

Mayer, R. E., Dyck, J. L., \& Cook, L. K. (1984). Techniques that help readers build mental models from scientific text: Definitions pretraining and signaling. Journal of Educational Psychology, 76, 1089-1105. doi:10.1037/0022-0663.76.6.1089.

Mayer, R. E., Hegarty, M., Mayer, S., \& Campbell, J. (2005). When static media promote active learning: Annotated illustrations versus narrated animations in multimedia learning. Journal of Experimental Psychology. Applied, 11, 256-265. doi:10.1037/1076-898X.11.4.256.

Meyer, B. J. F. (1975). The organization of prose and its effects on memory. New York: Elsevier.

Meyer, B. J. F., Brandt, D. M., \& Bluth, G. J. (1980). Use of top-level structure in text: Key for reading comprehension of ninth-grade students. Reading Research Quarterly, 16, 72-103. doi:10.2307/747349. 
Meyer, K., Rasch, T., \& Schnotz, W. (2009). Effects of animation's speed of presentation on perceptual processing and learning. Learning and Instruction, in press. doi:10.1016/j.learninstruc.2009.02.016.

Miller, G. A. (1956). The magical number seven, plus or minus two: Some limits on our capacity for processing information. Psychological Review, 63, 81-97. doi:10.1037/h0043158.

Miller, J. (1989). The control of attention by abrupt visual onsets and offsets. Perception \& Psychophysics, $45,567-571$.

Moreno, R. (2007). Optimizing learning from animations by minimizing cognitive load: Cognitive and affective consequences of signaling and segmentation methods. Applied Cognitive Psychology, 21, 765781. doi:10.1002/acp.1348.

Nagy, A. L., \& Winterbottom, M. (2000). The achromatic mechanism and mechanisms tuned to chromaticity and luminance in visual search. Journal of the Optical Society of America, 17, 369-379. doi:10.1364/ JOSAA.17.000369.

Paas, F. (1992). Training strategies for attaining transfer of problem-solving skill in statistics: A cognitiveload approach. Journal of Educational Psychology, 84, 429-434. doi:10.1037/0022-0663.84.4.429.

Paas, F., \& van Merriënboer, J. J. G. (1993). The efficiency of instructional conditions: An approach to combine mental-effort and performance measures. Human Factors, 35, 737-743.

Paas, F., \& van Merriënboer, J. J. G. (1994). Variability of worked examples and transfer of geometrical problem-solving skills: A cognitive-load approach. Journal of Educational Psychology, 86, 122-133. doi:10.1037/0022-0663.86.1.122.

Paas, F., Renkl, A., \& Sweller, J. (2003). Cognitive load theory and instructional design: Recent developments. Educational Psychologist, 38, 1-4. doi:10.1207/S15326985EP3801_1.

Paas, F., Van Gerven, P. W. M., \& Wouters, P. (2007). Instructional efficiency of animation: Effects of interactivity through mental reconstruction of static key frames. Applied Cognitive Psychology, 21, 783793. doi:10.1002/acp. 1349.

Park, O.-C., \& Hopkins, R. (1993). Instructional conditions for using dynamic visual displays. Instructional Science, 21, 427-449. doi:10.1007/BF00118557.

Pashler, H. (1988). Familiarity and visual change detection. Perception \& Psychophysics, 44, 369-378.

Ploetzner, R., \& Lowe, R. K. (2004). Dynamic visualizations and learning. Learning and Instruction, 14, 235-240. doi:10.1016/j.learninstruc.2004.06.001.

Rickards, J. P., Fajen, B. R., Sullivan, J. F., \& Gillespie, G. (1997). Signaling, note-taking, and field independence-dependence in text comprehension and recall. Journal of Educational Psychology, 89, 508-517. doi:10.1037/0022-0663.89.3.508.

Roy, M., \& Chi, M. T. H. (2005). The self-explanation principle in multimedia learning. In R. E. Mayer (Ed.), Cambridge handbook of multimedia learning, (pp. 271-286). New York: Cambridge University Press.

Schnotz, W., \& Lowe, R. K. (2008). A unified view of learning from animated and static graphics. In R. K. Lowe \& W. Schnotz (Eds.), Learning with animation: Research and design implications. New York: Cambridge University Press.

Seufert, T., \& Brünken, R. (2006). Cognitive load and the format of instructional aids for coherence formation. Applied Cognitive Psychology, 20, 321-331. doi:10.1002/acp.1248.

Shah, P., Mayer, R. E., \& Hegarty, M. (1999). Graphs as aids to knowledge construction. Journal of Educational Psychology, 91, 690-702. doi:10.1037/0022-0663.91.4.690.

Sweller, J. (1988). Cognitive load during problem solving: Effects on learning. Cognitive Science, 12, $257-285$.

Sweller, J. (1999). Instructional design in technical areas. Melbourne: ACER.

Tabbers, H. K., Martens, R. L., \& van Merriënboer, J. J. G. (2004). Multimedia instruction and cognitive load theory: Effects of modality and cueing. The British Journal of Educational Psychology, 74, 71-81. doi: $10.1348 / 000709904322848824$.

Theeuwes, J. (1991). Cross-dimensional perceptual selectivity. Perception \& Psychophysics, 50, $184-193$.

Theeuwes, J. (1992). Perceptual selectivity for color and form. Perception \& Psychophysics, 51, 599-606.

Thomas, L. E., \& Lleras, A. (2007). Moving eyes and moving thought: On the spatial compatibility between eye movements and cognition. Psychonomic Bulletin \& Review, 14, 663-668.

Treisman, A., \& Gelade, G. (1980). A feature integration theory of attention. Cognitive Psychology, 12, 97136. doi:10.1016/0010-0285(80)90005-5.

Treisman, A., \& Gormican, S. (1988). Feature analysis in early vision: Evidence from search asymmetries. Psychological Review, 95, 15-48. doi:10.1037/0033-295X.95.1.15.

Turatto, M., \& Galfano, G. (2000). Color, form and luminance capture attention in visual search. Vision Research, 40, 1639-1643. doi:10.1016/S0042-6989(00)00061-4.

Turatto, M., \& Galfano, G. (2001). Attentional capture by color without any relevant attentional set. Perception \& Psychophysics, 63, 286-297. 
Turatto, M., Galfano, G., Gardini, S., \& Mascetti, G. G. (2004). Stimulus-driven attentional capture: An empirical comparison of display-size and distance methods. Quarterly Journal of Experimental Psychology: Section A, 57, 297-324. doi:10.1080/02724980343000242.

Tversky, B. (2001). Spatial schemas in depictions. In M. Gattis (Ed.), Spatial schemas and abstract thought, (pp. 79-111). Cambridge: MIT.

Tversky, B., Zacks, J., Lee, P. U., \& Heiser, J. (2000). Lines, blobs, crosses, and arrows: Diagrammatic communication with schematic figures. In M. Anderson, P. Cheng \& V. Haarslev (Eds.), Theory and application of diagrams, (pp. 221-230). Berlin: Springer.

Tversky, B., Morrison, J., \& Bétrancourt, M. (2002). Animation: Can it facilitate? International Journal of Human-Computer Studies, 57, 247-262. doi:10.1006/ijhc.2002.1017.

Tversky, B., Heiser, J., Lozano, S., MacKenzie, R., \& Morrison, J. (2008). Enriching animations. In R. K. Lowe \& W. Schnotz (Eds.), Learning with animation: Research and design implications. New York: Cambridge University Press.

Van Oostendorp, H., \& Beijersbergen, M.J.(2007). Animated diagrams: Their effect on understanding, confidence and mental effort. Paper presented at the Bi-annual meeting of the European Association of Research on Learning and Instruction. Budapest, Hungary.

Wetzel, D. C., Radtke, P. H., \& Stern, H. W. (1994). Instructional effectiveness of video media. Hillsdale/ Mahwah, NJ: Lawrence Erlbaum.

Winn, W. D. (1993). A constructivist critique of the assumptions of instructional design. In T. Duffy, J. Lowyck \& D. Jonassen (Eds.), Designing environments for constructive learning. New York: Springer.

Yantis, S., \& Egeth, H. E. (1999). On the distinction between visual salience and stimulus-driven attentional capture. Journal of Experimental Psychology. Human Perception and Performance, 25, 661-676. doi:10.1037/0096-1523.25.3.661.

Yantis, S., \& Jonides, J. (1984). Abrupt visual onsets and selective attention: Evidence from visual search. Journal of Experimental Psychology. Human Perception and Performance, 10, 601-621. doi:10.1037/ 0096-1523.10.5.601. 